\title{
IMAGE
}

\section{Insights Image for "Dysregulation of Notch signaling in cardiac mesenchymal cells of patients with Tetralogy of Fallot"}

Ivan Kozyrev ${ }^{1}$, Pavel Dokshin ${ }^{1,2}$, Aleksandra Kostina ${ }^{1,3}$, Artem Kiselev ${ }^{1}$, Elena Ignatieva ${ }^{1}$, Alexey Golovkin ${ }^{1}$, Tatiana Pervunina ${ }^{1}$, Evgeny Grekhov ${ }^{1}$, Mikhail Gordeev ${ }^{1}$, Anna Kostareva ${ }^{1}$ and Anna Malashicheva ${ }^{1,2,3}$

Pediatric Research (2020) 88:139; https://doi.org/10.1038/s41390-020-0848-z

Notch signaling in the pathogenesis of the Tetralogy of Fallot represents a puzzle interacting with many components. ${ }^{1}$ If we put all its components together, the result will be a structurally and functionally normal heart, but if one or several details fall out, it will be impossible to get a complete picture. Coordinated action of Notch genes is a very important component of this puzzle.

\section{REFERENCE}

1. Kozyrev, I. et al. Dysregulation of Notch signaling in cardiac mesenchymal cells of patients with tetralogy of Fallot. Pediatr. Res. https://doi.org/10.1038/s41390-0200760-6 (2020).

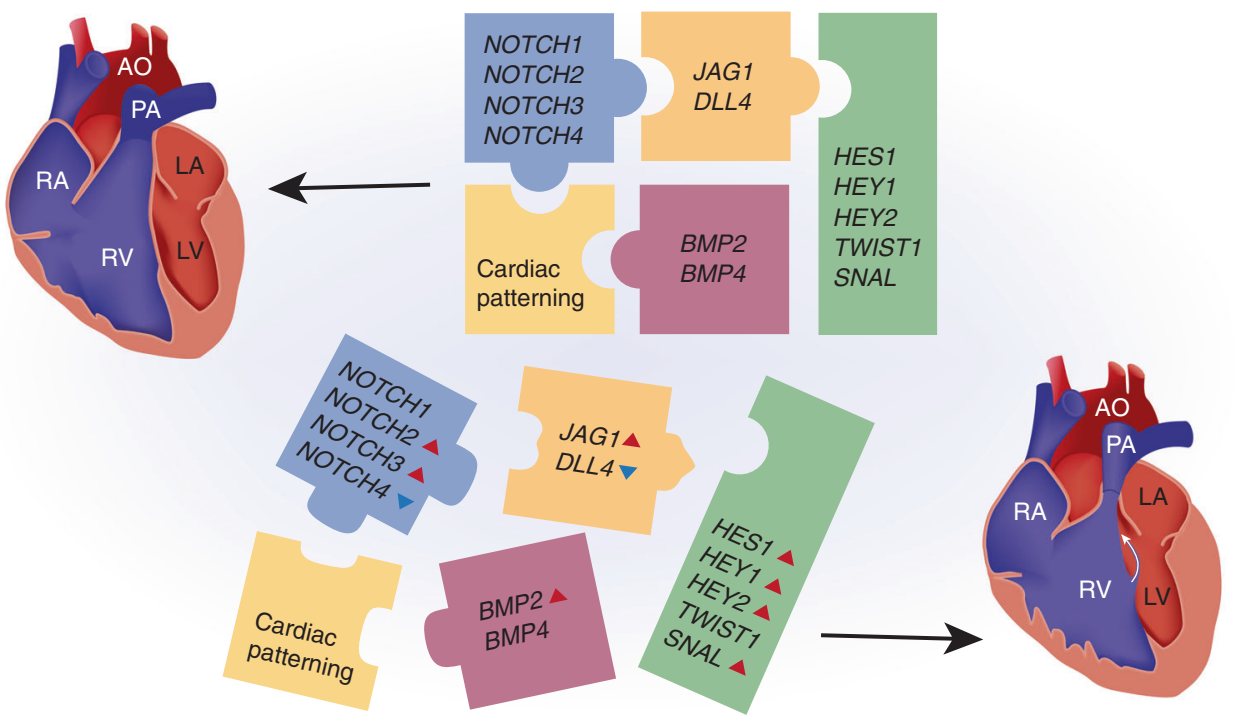

\footnotetext{
'Almazov National Medical Research Centre, St. Petersburg, Russia; ${ }^{2}$ Saint Petersburg State University, Faculty of Biology, St. Petersburg, Russia and ${ }^{3}$ Institute of Cytology, Russian Academy of Sciences, St. Petersburg, Russia

Correspondence: Anna Malashicheva (amalashicheva@gmail.com)
}

Received: 6 March 2020 Accepted: 6 March 2020

Published online: 13 March 2020 